تأثير تدرج الحماية الحجرية على النحر الموضعي حول دعامات الجسور

الاكتور خالد صديق الثيخ علي

قسم هندسة الموارد المائية
منار سفر الياس ميخائيل الصفار

قسم هندسة الموارد المائية

\title{
الخلاصة
}

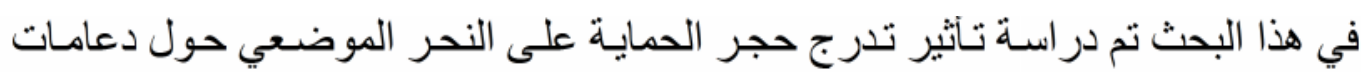

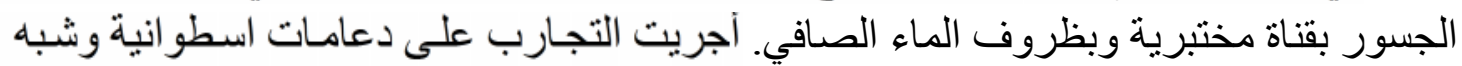

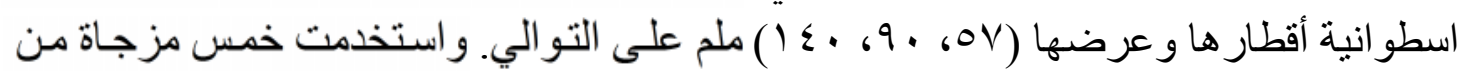

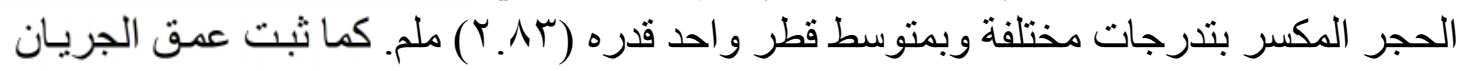

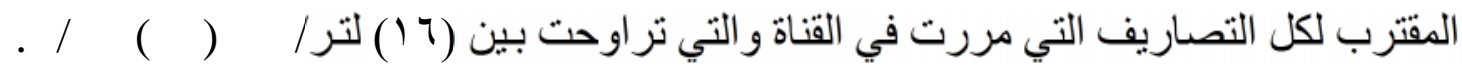

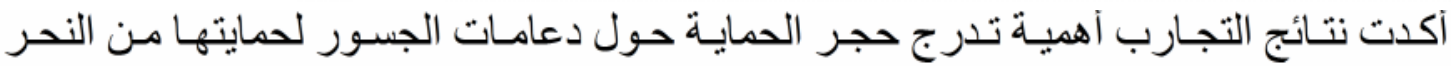

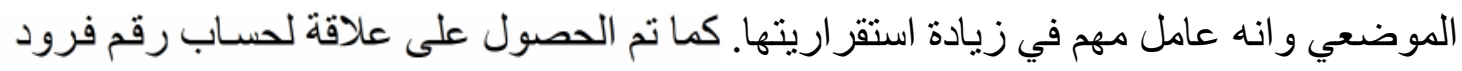

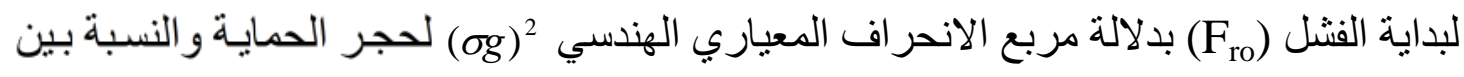
و وبمعامل تحديد قدره

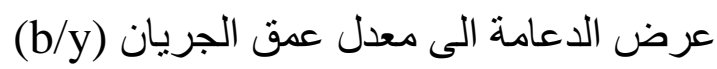

$$
\begin{aligned}
& \text {. ( . ) } \\
& \text { حجر الحماية، دعامات الجسور. } \\
& \text { الكلمات الدالة: }
\end{aligned}
$$

\section{Riprap Gradation Effect On Local Scour Around Bridge Piers}

\author{
Manar Safar Alyas Michael Al-Saffar Dr. Khalid Saddiq Al- \\ Shaikh-Ali
}

Dept. of Water Resources Eng.

Asst. Prof. Dept.

of Water Resources

Abstract 
In this paper, an experimental flume study was carried out on riprap gradation effects on local scour around bridge piers under clear water condition . Experiments were performed on circular and semi-circular piers having diameters and widths of $(57,90,140) \mathrm{mm}$, respectively. Five mixtures of riprap were used having different gradations and the same mean grain size of $(2.83) \mathrm{mm}$. The approach depth was maintained constant for all discharges which ranged between (16) 1/s to (24) $1 / \mathrm{s}$.

Experimental results indicated the importance of riprap gradation around bridge piers and that it is an important factor on its stability. Furthermore a formula for determining Froude number $\left(\mathrm{F}_{\mathrm{ro}}\right)$ at the threshold of riprap failure in terms of the variance of riprap, $(\sigma g)^{2}$, the ratio between pier width to the average flow depth $(\mathrm{b} / \mathrm{y})$, and pier shape factor $(k)$, with $\left(R^{2}=0.82\right)$ was obtained.

Subject headings: Scour, Riprap, Bridge piers.

قبل في 2007/6/10

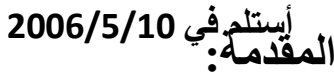

إن الدعامات التي تقام عليها الجسور تحدث تغيير أ في خواص الجريـان بالأنهار الرسوبية

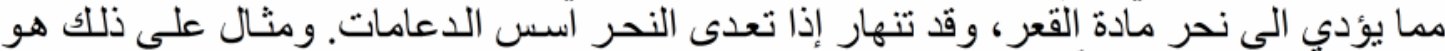

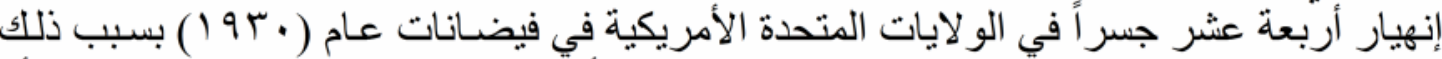

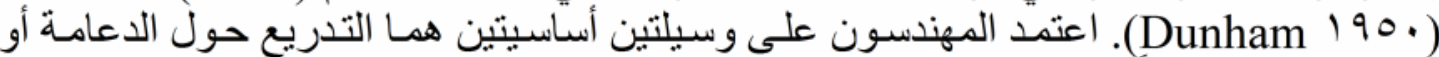

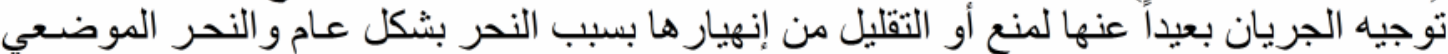

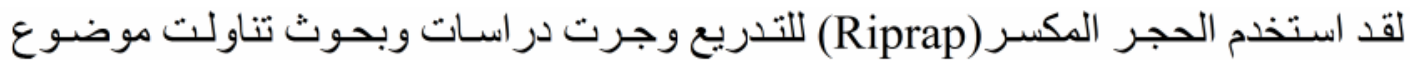

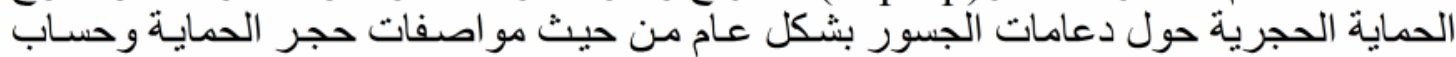

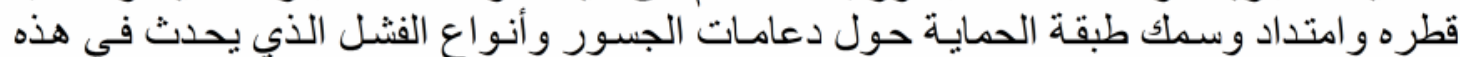

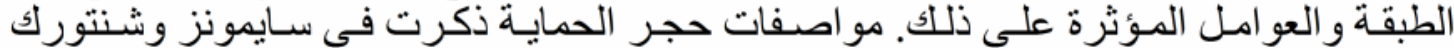
(Simons and Senturk 19V7)

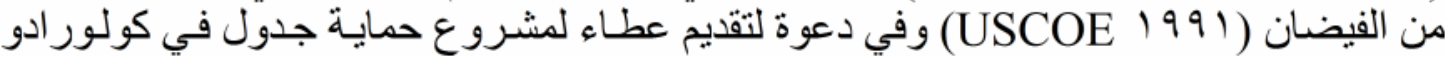
(DACE من الفيضان (لفضان 
البحوث التي تناولت موضوع تصميم طبقة الحماية الحجرية حول دعامات الجسور تللك التي واني

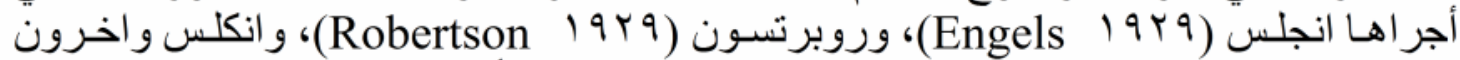

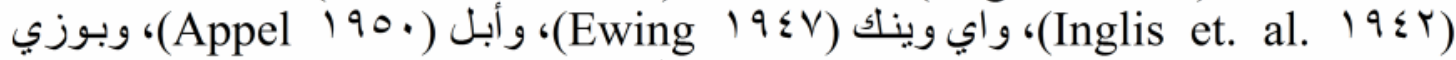

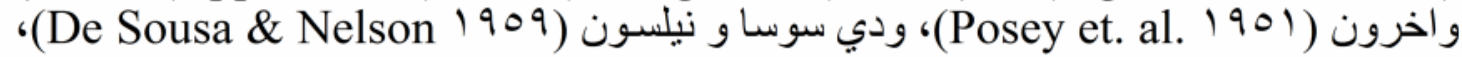

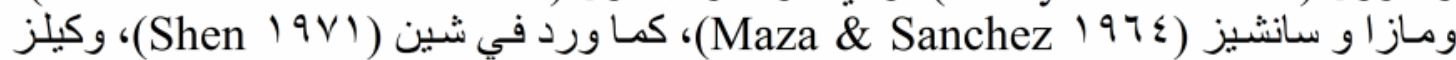

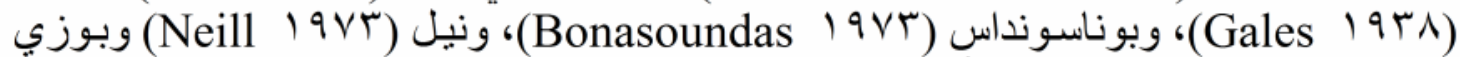

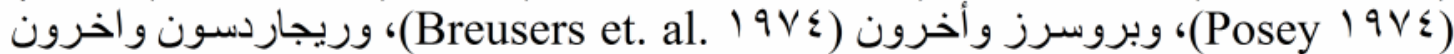
Chiew Sما ورد في جيو (Parola) ) (Richardson et. al.

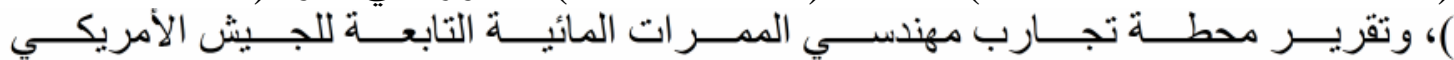

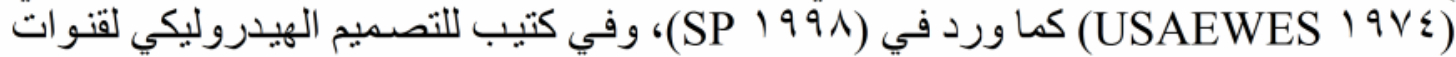

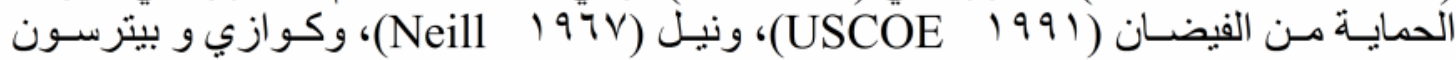

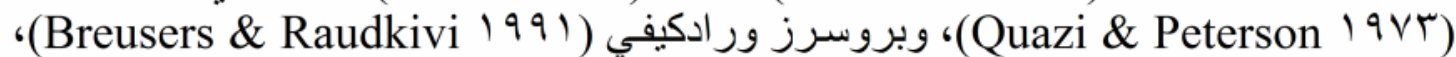

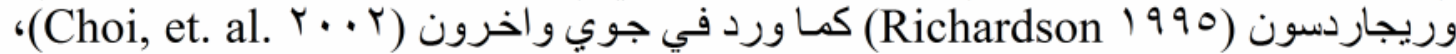

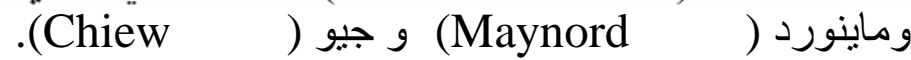

أما فيما بتعلق بأنو اع الفشل الذي بحدث في طبقة الحماية حول الدعامة فالبحوث التي أجر اهـا

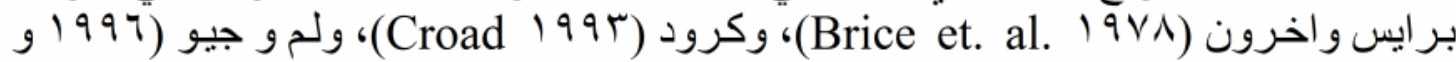

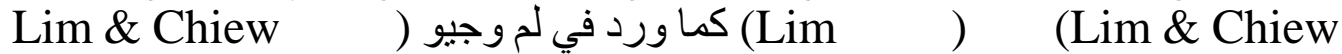

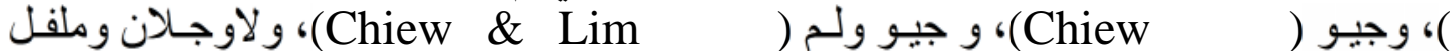

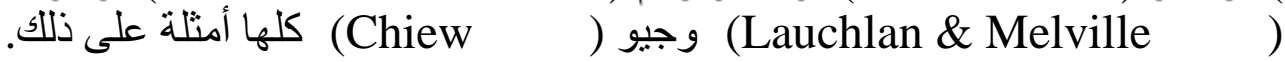

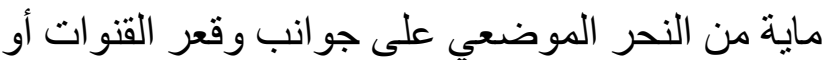

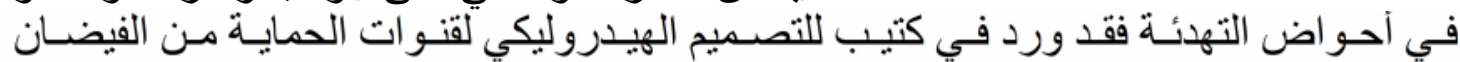

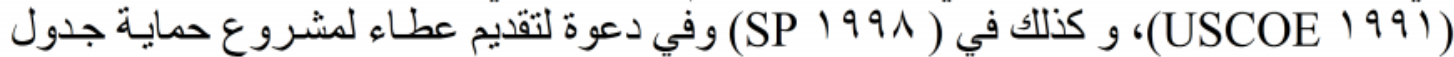
في كولور ادو من الفيضان ( ) DACE)

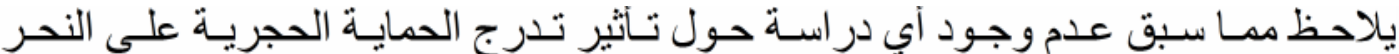

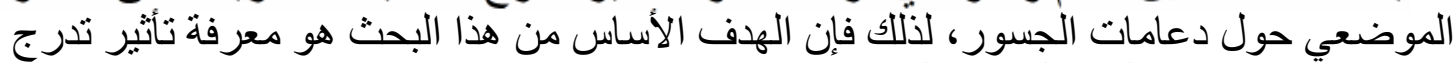

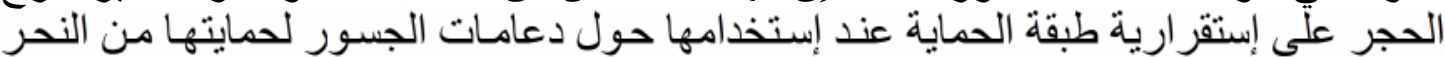
الموضعي و الى أي مدى يمكن لهذا التدرج أن يكون فاعلاً في ذلك وبظروف لئ هيدروليكية مختلفة.

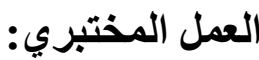

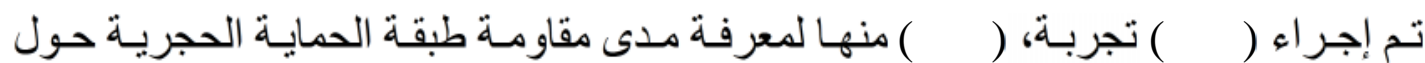

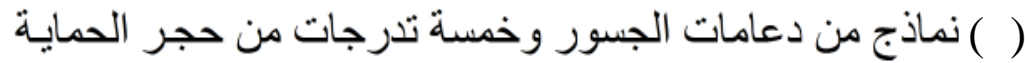

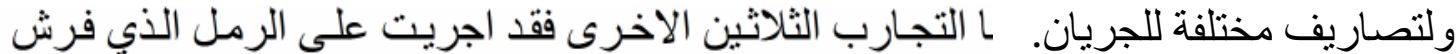

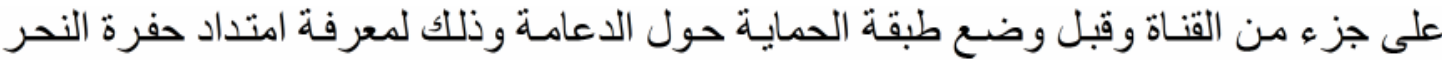

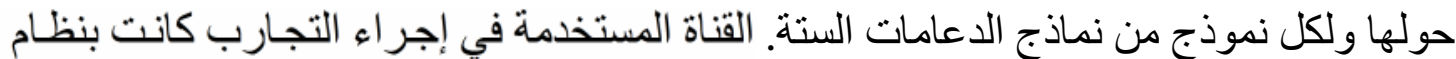

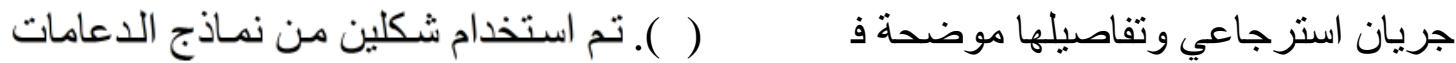

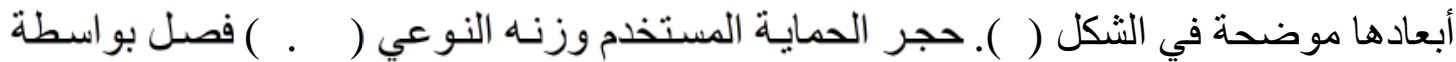

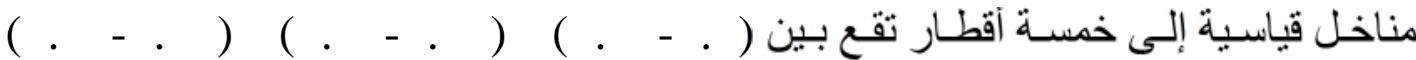

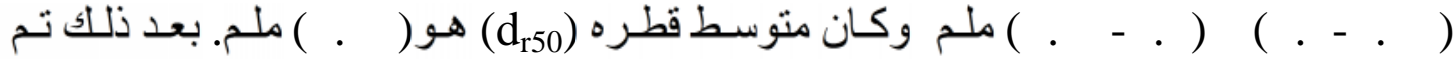
تحضير خمس مزجات، كل مزجة احتوت على نسب وزنية مختلفة لتحديد تدرجات الحجر من 
كل قطر من الأقطار المذكورة انفا وللحصول على مربع إنحر اف معياري

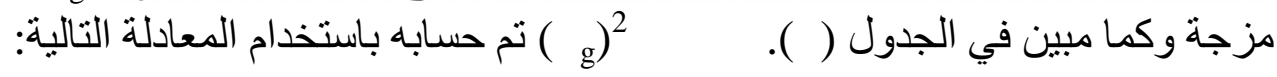
$\left(\sqrt{\frac{d_{84.1}}{d_{15.9}}}\right)^{2}$

$\left(\sigma_{\mathrm{g}}\right)^{2}=$

( ) تم تمثيل كل مزجة بمنحني تر اكمي على أساس الوزن.

الجدول (1) نسبة الأقطار للمزجات الخمس من حجر الحماية على أساس الوزن

\begin{tabular}{|c|c|c|c|c|c|}
\hline قلطر & 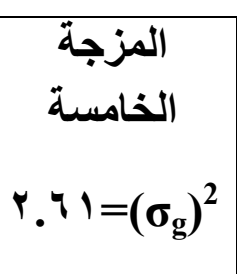 & 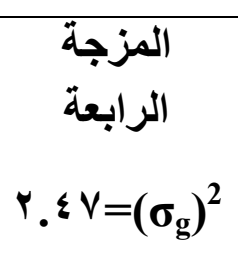 & 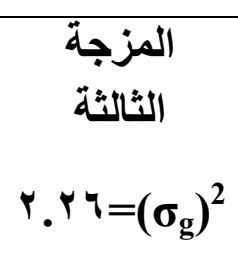 & $\begin{array}{c}\text { الثزانية } \\
\text { الثزة } \\
1.9\left(\sigma_{g}\right)^{2}\end{array}$ & 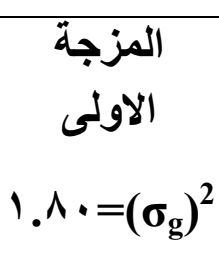 \\
\hline (ملم) & \multicolumn{5}{|c|}{ النسب المئوية للحجر المتبقي (\%) } \\
\hline- & & & & & \\
\hline- & & & & & \\
\hline- & & & & & \\
\hline- & & & & & \\
\hline- & & & & & \\
\hline & & & & & \\
\hline
\end{tabular}

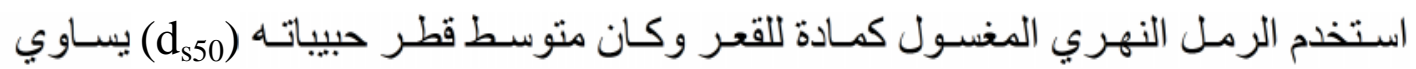

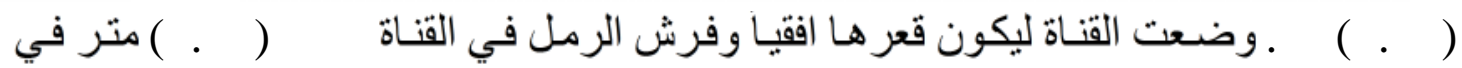

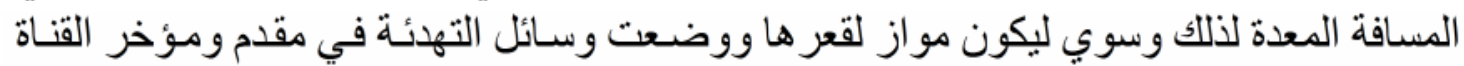

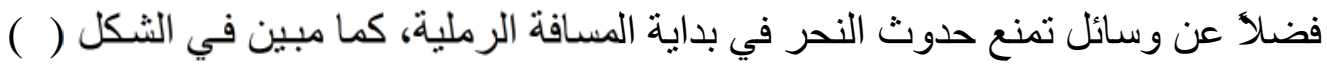

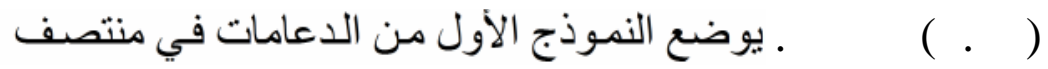

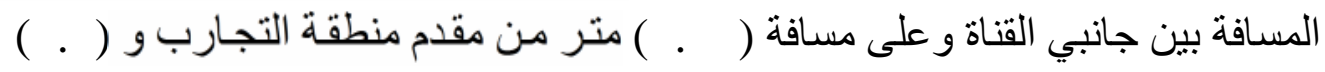

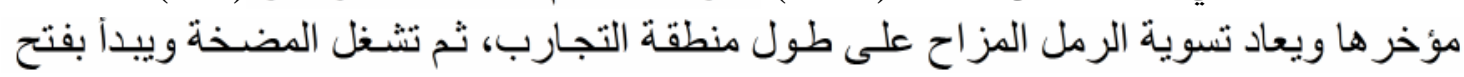

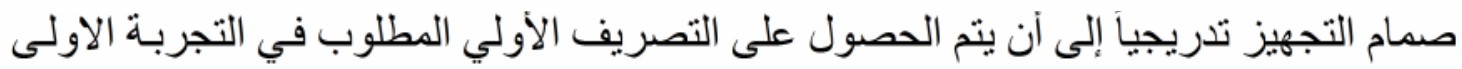

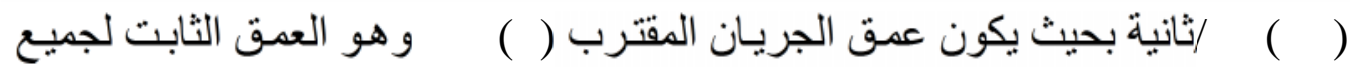


التصاريف في التجارب اللاحقة، وبعدها يترك الجريان لمدة سـاعتين ثم يز اد التصريف الأولي

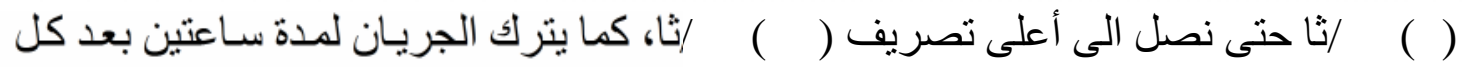

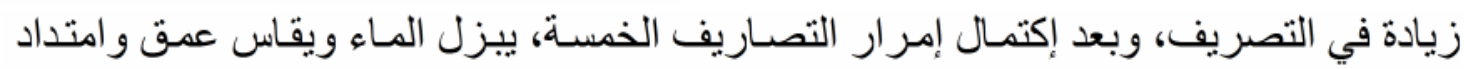

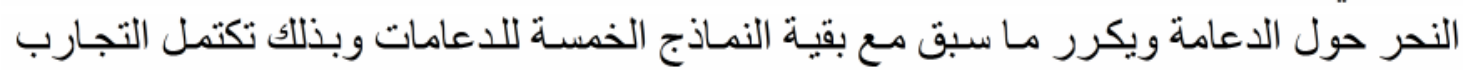

من التجارب الاولى تبين بـأن تأثير الدعامـة على النحر الموضـي يمكن تحديده بمقدار

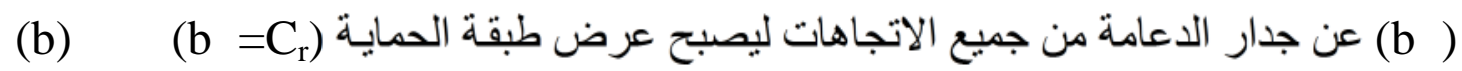

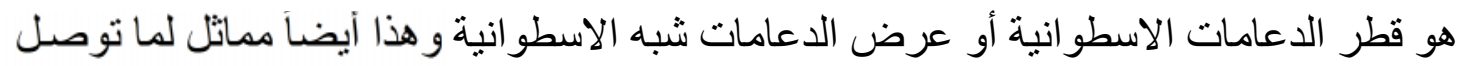

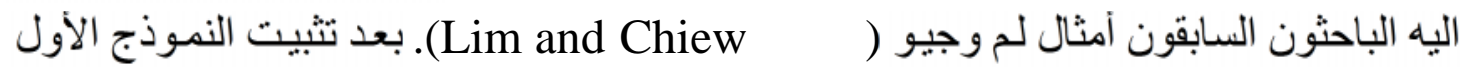

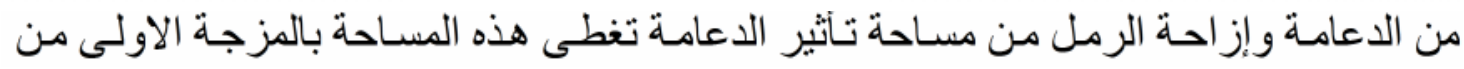

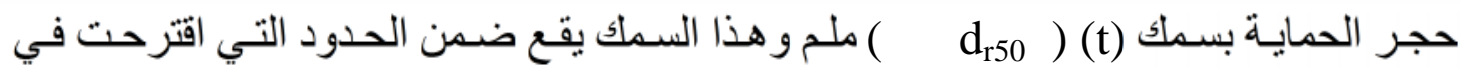

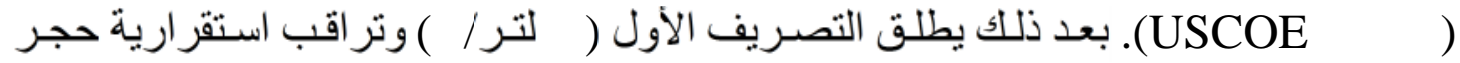

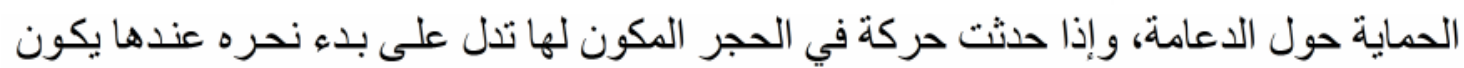

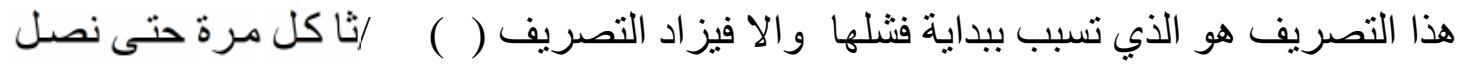

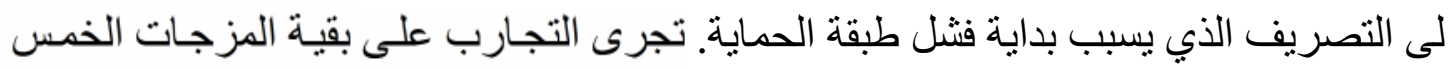

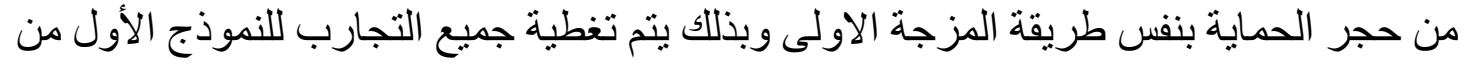

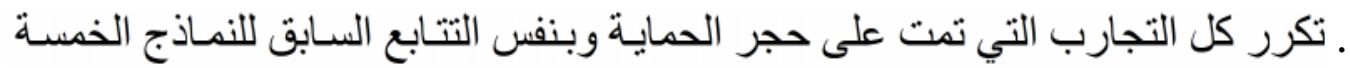
تنقية من الدعامات وبذلك يكون عدد التجارب التي اجريت حول استقر ارية حجر الحماية

تم قياس التصريف بو اسطة سد غاطس ذو ثلمة مثلثة يقع في مقدم القناة بعد آن اجريت لـه

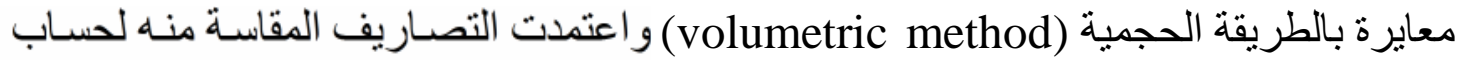

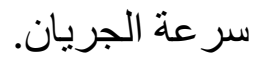



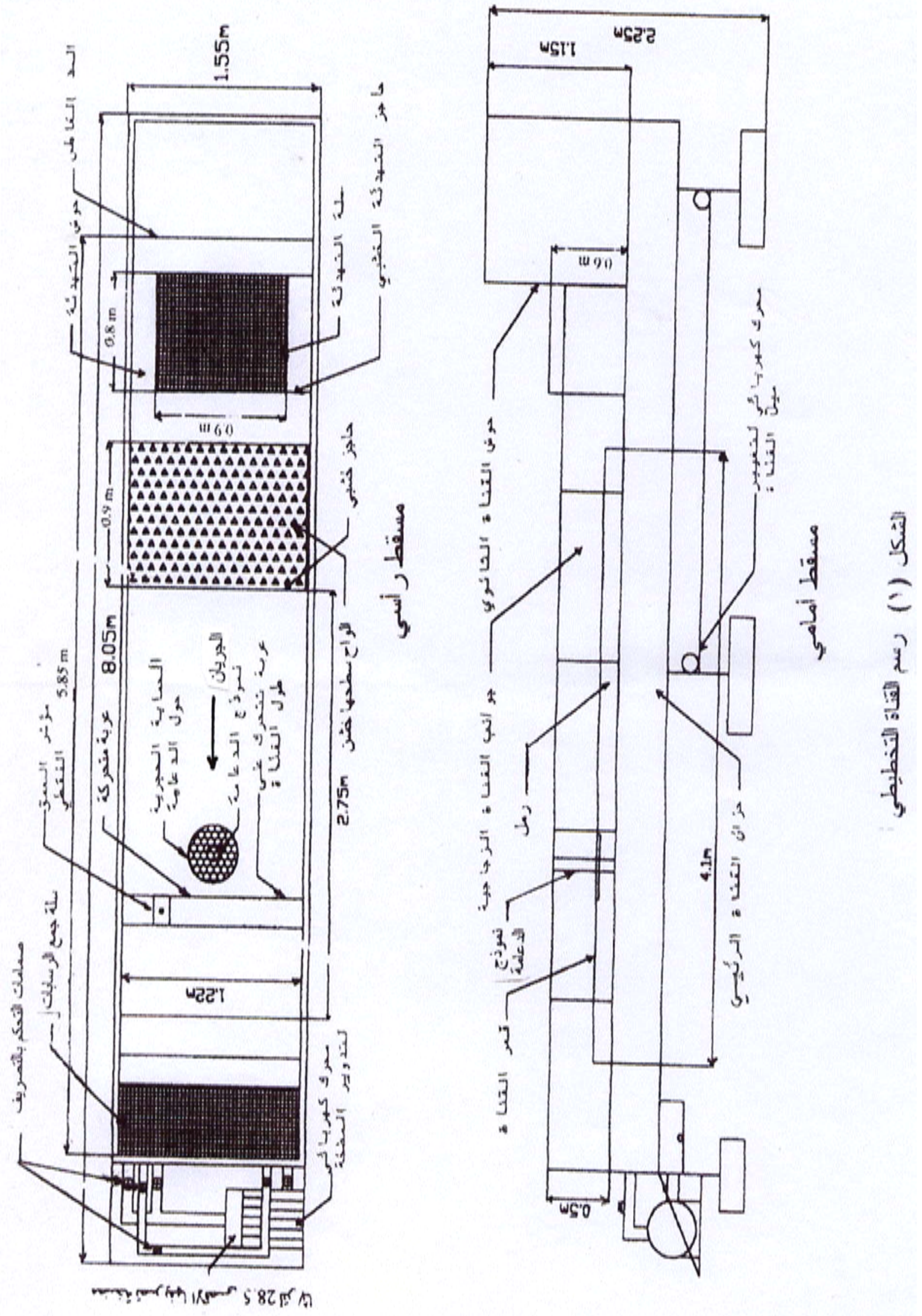


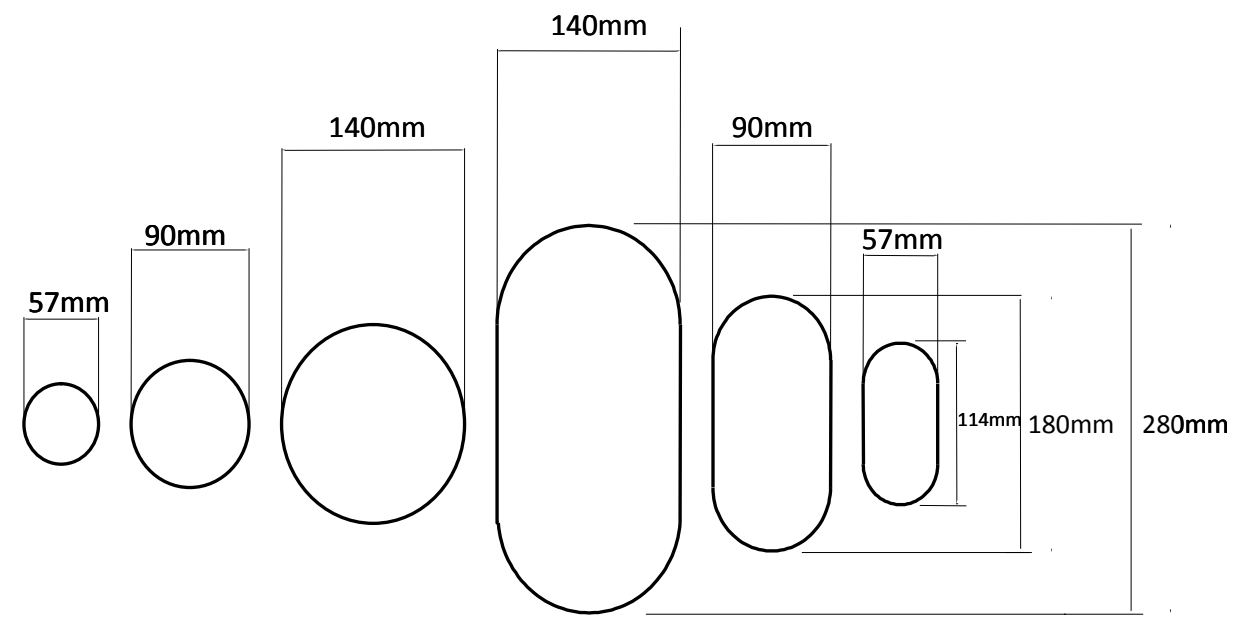

الشكل (Y) مخطط يبين ابعاد الدعامات

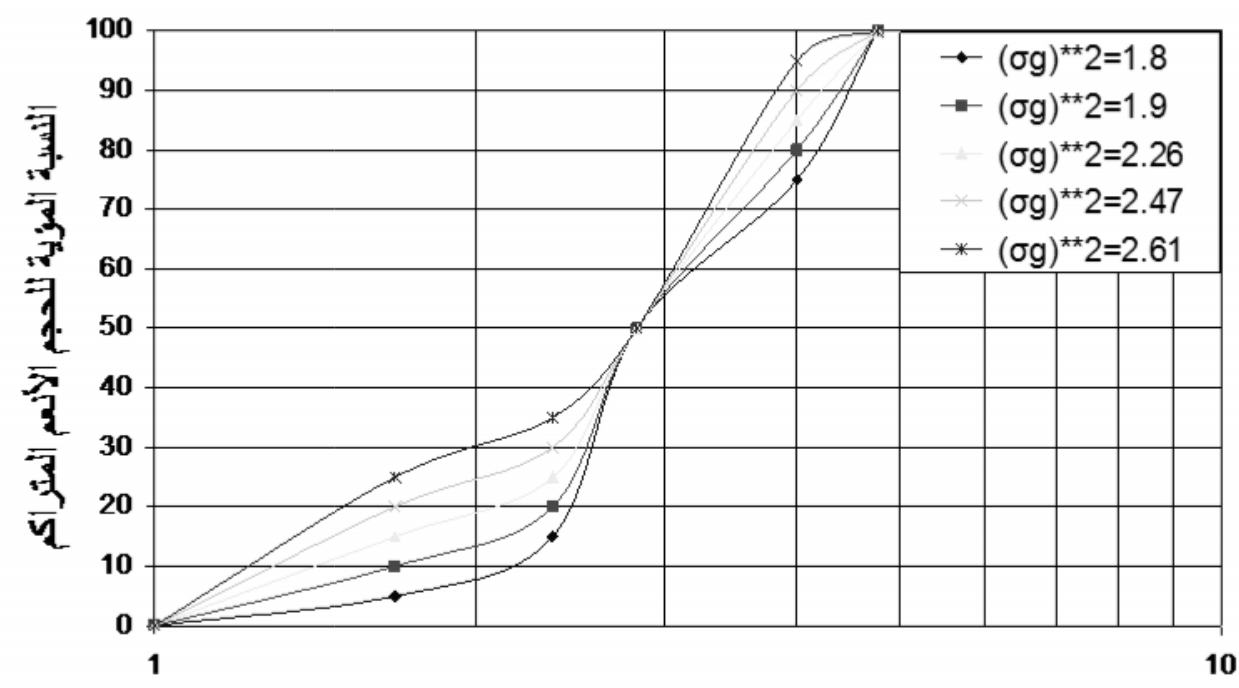

حجم صييات الحجر (ملم)

الشكل (ب) المنحنيات التر اكمية التي تمثل المزجات الخمس 
إن ظـاهرة النحر حول دعامـة الجسر تعتمد على مجموعة من المتغيرات. هذه المتغيرات ادخلت في طريقة التحليل البعدي فتم الحصول فلح على العلاقة التالية:

Failure $=f\left(\frac{L}{y}, \frac{b}{y}, \frac{d_{r 50}}{y} F_{r o}, R_{e}, \frac{\rho_{s}}{\rho_{w}}, \frac{d_{s 50}}{y}, \frac{\rho_{r}}{\rho_{w}}, \frac{t}{y}, \frac{c_{r}}{y},\left(\sigma_{g}\right)^{2}, k\right)$

بعد إهمال تأثير رقم رينولدز و النسب الثابتة الواردة سابقأ تختصر المعادلة ( ) إلى ما يلي:

$$
\text { Failure }=f\left(F_{r o},\left(\sigma_{g}\right)^{2}, k, \frac{b}{y}, \frac{c_{r}}{y}, \frac{L}{y}\right)
$$

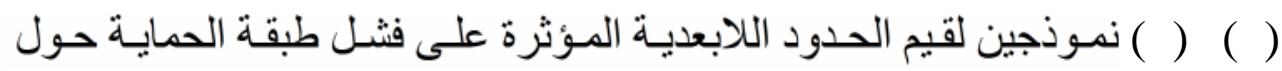

الدعامات الاسطو انية وشبه الاسطو انية، على التو الي.

الجدول (r) قيم الحدود اللابعدية المؤثرة على فثل طبقة الحماية حول الدعامات الاسطوانية $* \mathrm{M}_{1,(\mathrm{~b})}$

\begin{tabular}{|c|c|c|c|c|c|c|c|}
\hline 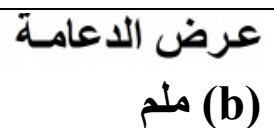 & تصــريف الفشـــل & $F_{\text {ro }}$ & $\left(\sigma_{\mathrm{g}}\right)^{2}$ & $\mathbf{K}$ & $\mathbf{b} / \mathbf{y}$ & $\mathbf{C}_{\mathbf{r}} / \mathbf{y}$ & $\mathbf{L} / \mathbf{y}$ \\
\hline & & . & . & . & . & • & . \\
\hline & & . & r & • & . & . & . \\
\hline & & . & & & . & . & . \\
\hline
\end{tabular}

$\mathrm{M}_{2,(\mathrm{~b})}$

\begin{tabular}{|c|c|c|c|c|c|c|c|}
\hline 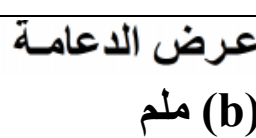 & تصريف الفشل (Q) & $\mathbf{F}_{\text {ro }}$ & $\left(\sigma_{g}\right)^{2}$ & $\mathbf{k}$ & $\mathbf{b} / \mathbf{y}$ & $\mathbf{C}_{\mathrm{r}} / \mathbf{y}$ & $\mathbf{L} / \mathbf{y}$ \\
\hline & & • & • & & - & $\cdot$ & . \\
\hline & & . & & & . & • & . \\
\hline & & & & & . & . & . \\
\hline
\end{tabular}




\begin{tabular}{|c|c|c|c|c|c|c|c|}
\hline عرض الاعامـة & تصــريف الفشــلـل & $F_{\text {ro }}$ & $\left(\sigma_{g}\right)^{2}$ & $\mathbf{k}$ & $\mathbf{b} / \mathbf{y}$ & $\mathbf{C}_{\mathrm{r}} / \mathbf{y}$ & $\mathbf{L} / \mathbf{y}$ \\
\hline & & . & $0^{\circ}$ & & . & . & . \\
\hline & & . & . & . & . & • & . \\
\hline & & . & & . & . & . & . \\
\hline
\end{tabular}

$\mathrm{M}_{4,(\mathrm{~b})}$

\begin{tabular}{|c|c|c|c|c|c|c|c|}
\hline 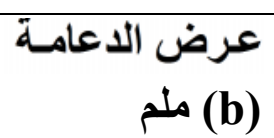 & تصــريف الفشـــل & $F_{\text {ro }}$ & $\left(\sigma_{\mathrm{g}}\right)^{2}$ & $\mathbf{k}$ & $\mathbf{b} / \mathbf{y}$ & $\mathbf{C}_{\mathbf{r}} / \mathbf{y}$ & $\mathbf{L} / \mathbf{y}$ \\
\hline & & . & . & . & . & . & . \\
\hline & & . & & & . & . & \\
\hline & & & & & . & . & \\
\hline
\end{tabular}

$\mathrm{M}_{5,(\mathrm{~b})}$

\begin{tabular}{|c|c|c|c|c|c|c|c|}
\hline 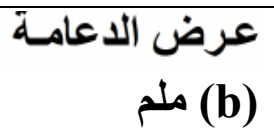 & تصــريف الفثـلـ & $F_{r o}$ & $\left(\sigma_{\mathrm{g}}\right)^{2}$ & $\mathbf{k}$ & $\mathbf{b} / \mathbf{y}$ & $\mathbf{C}_{\mathrm{r}} / \mathbf{y}$ & $\mathbf{L} / \mathbf{y}$ \\
\hline & & . & . & . & . & 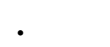 & . \\
\hline & & . & & . & . & . & \\
\hline & & . & & & . & . & \\
\hline
\end{tabular}

الجدول (") قيم الحدود اللابعدية المؤثرة على فثل طبقة الحماية حول الدعامات شبه الاسطو انية 


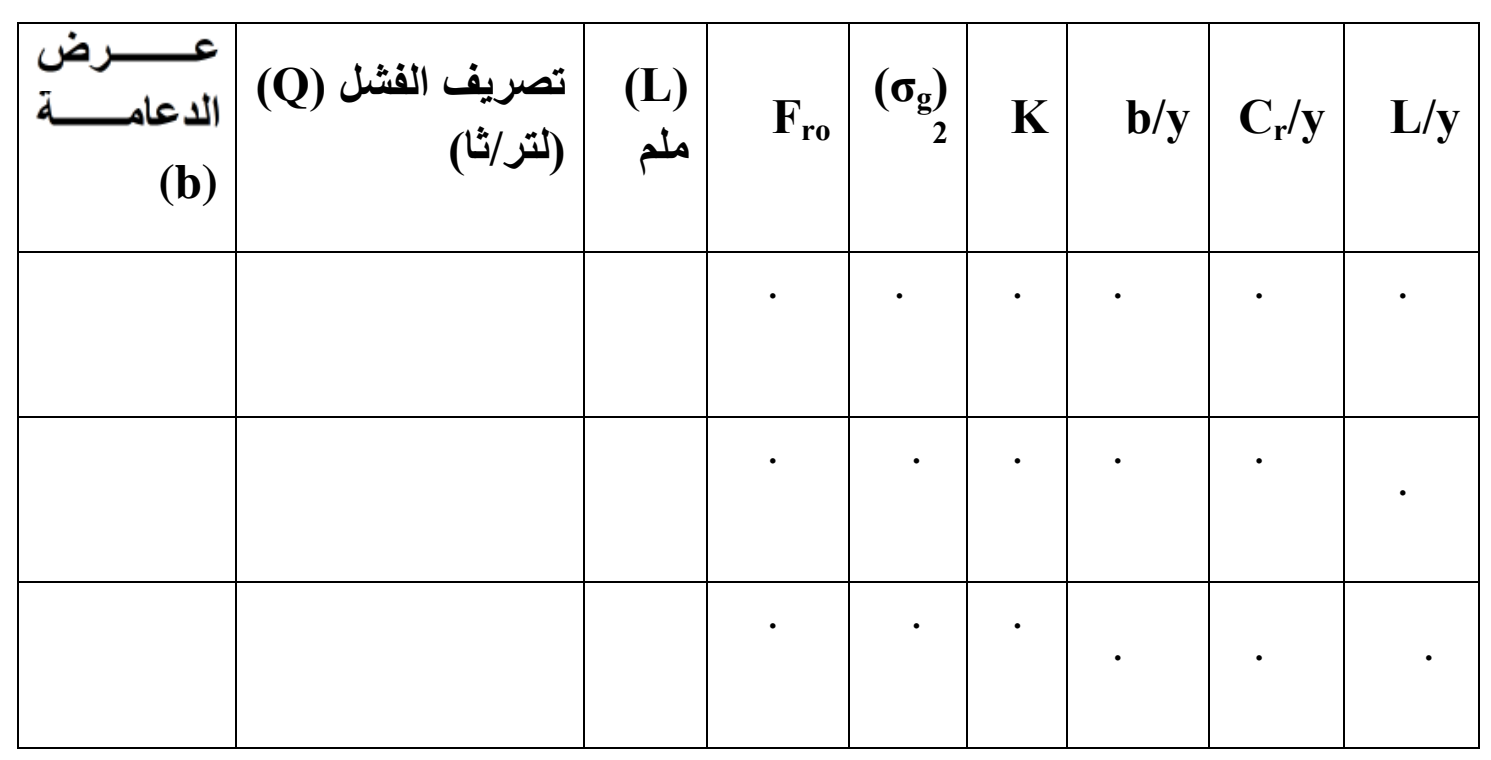

$\mathrm{M}_{2, \text { (b) }}$

\begin{tabular}{|c|c|c|c|c|c|c|c|c|}
\hline 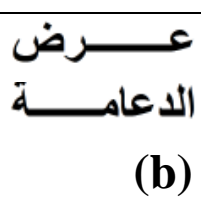 & 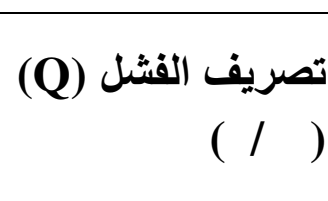 & $(\mathbf{L})$ & $\mathbf{F}_{\mathbf{r o}}$ & $\left(\sigma_{g}\right)$ & K & $\mathbf{b} / \mathbf{y}$ & $\mathbf{C}_{\mathrm{r}} / \mathbf{y}$ & $\mathbf{L} / \mathbf{y}$ \\
\hline & & & . & . & . & & . & . \\
\hline & & & • & & & & & \\
\hline & & & & & & & & \\
\hline & & & & & & & & \\
\hline
\end{tabular}

$\mathrm{M}_{3,(\mathrm{~b})}$

\begin{tabular}{|c|c|c|c|c|c|c|c|c|}
\hline 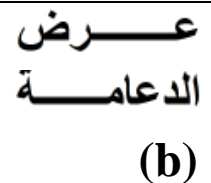 & 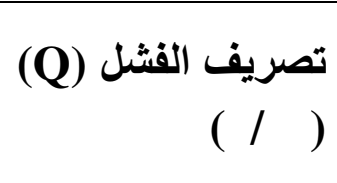 & (L) & $\mathbf{F}_{\text {ro }}$ & $\left(\sigma_{\mathrm{g}}\right)$ & $\mathbf{K}$ & $\mathbf{b} / \mathbf{y}$ & $\mathbf{C}_{\mathbf{r}} / \mathbf{y}$ & $\mathbf{L} / \mathbf{y}$ \\
\hline & & & • & . & . & & . & . \\
\hline & & & . & . & . & & • & . \\
\hline & & & & & & & & \\
\hline
\end{tabular}




\begin{tabular}{|l|l|l|l|l|l|l|l|l|}
\hline & & & $\cdot$ & $\cdot$ & $\cdot$ & & $\cdot$ & $\cdot$ \\
\hline
\end{tabular}

$\mathrm{M}_{4,(\mathrm{~b})}$

\begin{tabular}{|c|c|c|c|c|c|c|c|c|}
\hline 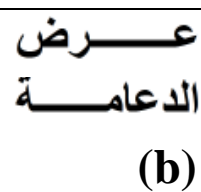 & 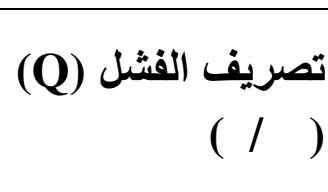 & $(\mathbf{L})$ & $F_{\text {ro }}$ & $\left(\sigma_{g}\right)$ & $\mathbf{K}$ & $\mathbf{b} / \mathbf{y}$ & $\mathbf{C}_{\mathbf{r}} / \mathbf{y}$ & $\mathbf{L} / \mathbf{y}$ \\
\hline & & & . & - & - & & . & . \\
\hline & & & . & . & - & & . & . \\
\hline & & & & . & - & & & \\
\hline & & & & & & & & \\
\hline
\end{tabular}

$\mathrm{M}_{5,(\mathrm{~b})}$

\begin{tabular}{|c|c|c|c|c|c|c|c|c|}
\hline 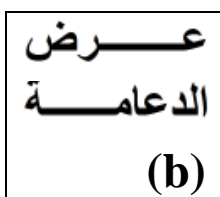 & 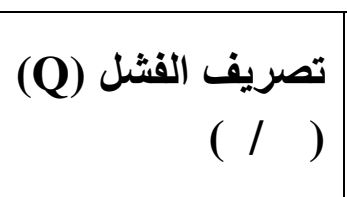 & (L) & $\mathbf{F}_{\mathbf{r o}}$ & $\begin{array}{r}\left(\sigma_{g}\right) \\
\end{array}$ & $\mathbf{K}$ & $\mathbf{b} / \mathbf{y}$ & $\mathbf{C}_{\mathrm{r}} / \mathbf{y}$ & $\mathbf{L} / \mathbf{y}$ \\
\hline & & & . & . & . & . & • & . \\
\hline & & & . & . & . & - & - & \\
\hline & & & . & & • & & & \\
\hline & & & & & & & & \\
\hline
\end{tabular}


لغرض إيجاد علاقة بين فثنل طبقة الحماية الحجرية حول الدعامـة و المتغير ات التابلابعدية.

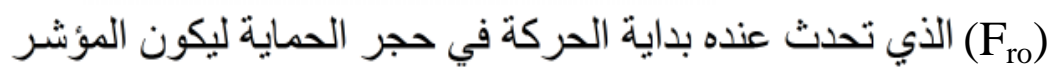

على بداية الفتنل الحاصل فيها.

- - العلاقة بين رقم فرود (Fo) ومربع الإنحراف المعياري الهندسي لحجر الحماية (og) :

لقد تم اعتماد الانحر اف المعياري الهندسي 2( رسمت العلاقـة بـين (Fo (

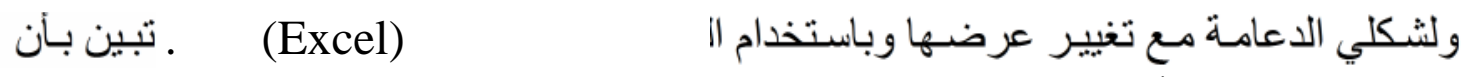
العلاقة الخطية هي أفضل العلاقات بينهما وكما يلي:

$$
F_{r o}=a_{1}+b_{1} \times\left(\sigma_{g}\right)^{2}
$$

$$
\text { bي ثوابت المعادلة. } \mathrm{b}_{1}, \mathrm{a}_{1}
$$

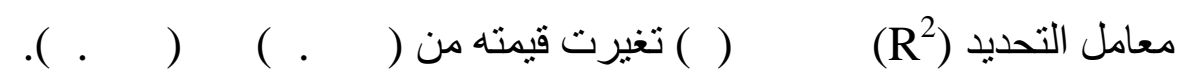

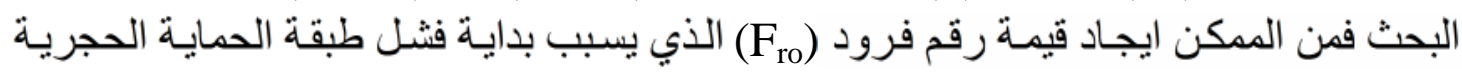

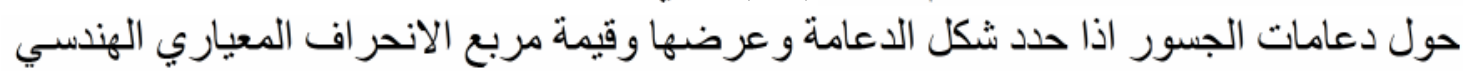
$\quad(\sigma g)^{2}$

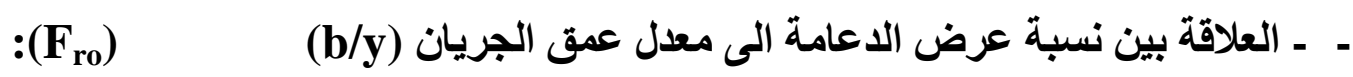

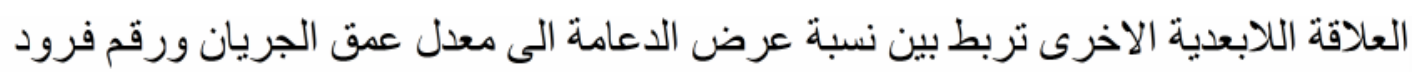

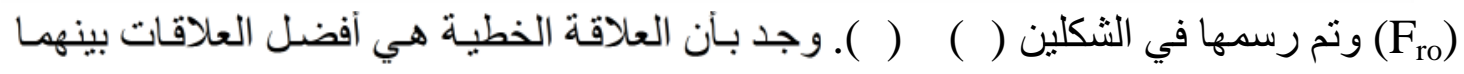
وكما يلي: 


$$
F_{r o}=a_{2}+b_{2} \times\left(\frac{b}{y}\right)
$$

$$
\text { هي ثو ابت المعادلة. } \text { b }_{2} \quad a_{2}
$$

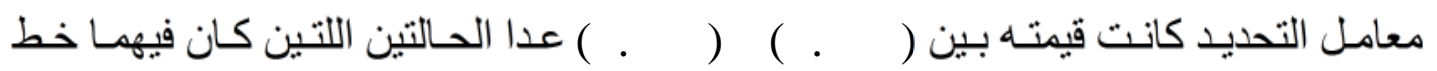

العلاقة مواز لقيم النسبة (b/y).

- - العلاقة بين نسبة عرض طبقة الحماية الحجرية إلى معدل عمق الجريـان (Cr/y)

$$
\text { :(F ro }
$$

علاقة لا بعدية اخرى نربط بين نسبة عرض طبقة الحماية الحجرية إلى معدل عمق الجريـان

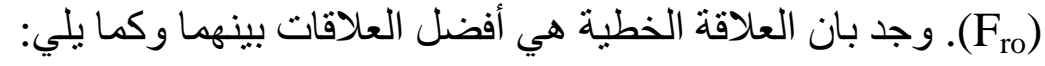

$F_{r o}=a_{3}+b_{3}\left(\frac{C_{r}}{y}\right)$

$$
\text { هي ثو ابت المعادلة. } \mathrm{b}_{3} \quad \mathrm{a}_{3}
$$

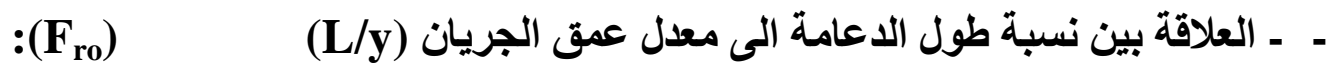
علاقة لا بعدية رابعة تربط بين نسبة طول الدعامة إلى معدل عمق الجريان ورقم فرود (Fro). وجد بان العلاقة الخطية هي أفضل العلاقات بينهما بلنيل وكما يلي:

$F_{r o}=a_{4}+b_{4}\left(\frac{L}{y}\right)$

$$
\text { هي ثو ابت المعادلة. } \text { b }_{4} \quad a_{4}
$$

$$
\text { ـ العلاقة بين شكل الدعامة ورقم فرود (F) }
$$

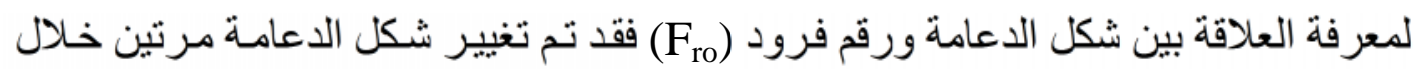

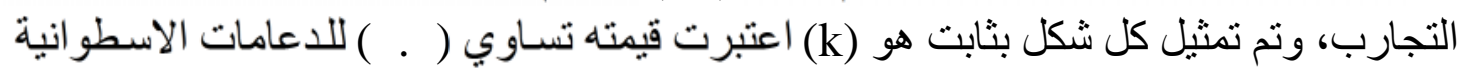

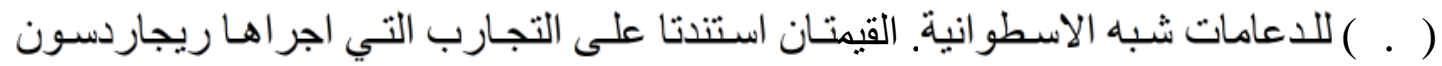

.(Richardson et. al. 1991) 
- تأثير المتغيرات البعدية على بداية الفثل حول الدعامة:

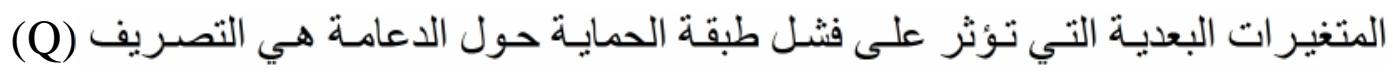

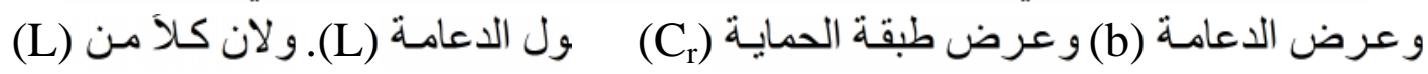

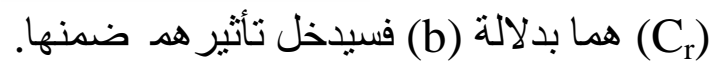

- ـ تأثير التصريف (Q) على بداية فثنل طبقة الحماية:

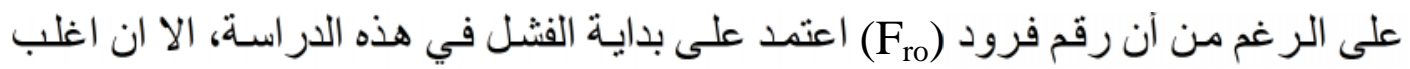

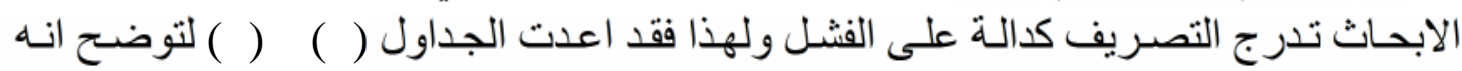

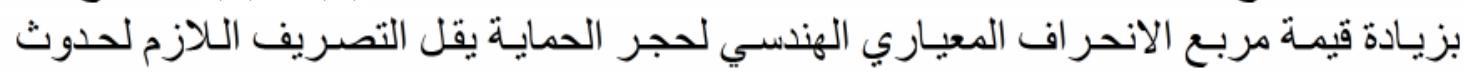

( ) نسبة الزيادة في قيمة مربع الانحراف المعياري الهندسي لحجر الحماية مع نسبة

النقصان في تصريف الفثل للاعامات الاسطوانية الأنية

\begin{tabular}{|c|c|c|}
\hline \multicolumn{2}{|c|}{ نسبة النقصان في التصريف عند بداية الفشل (Q) (\%) } & \multirow{2}{*}{ نس (\% } \\
\hline$(\%)$ & 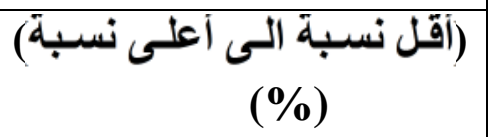 & \\
\hline$*$ & (. . & \\
\hline & $(.-)$. & \\
\hline & $(.-)$. & \\
\hline & $(.-)$. & \\
\hline
\end{tabular}

الزيادة في قيمة مربع الإنحراف المعياري الهندسي لحجر الحماية مع نسبة النقصان في تصريف الفشل للاعامات شبه الاسطو الية النية

\begin{tabular}{|c|c|c|}
\hline \multicolumn{2}{|c|}{ نسبة النقصان في التصريف عند باية الفشل (Q) (\%) } & \multirow{2}{*}{ 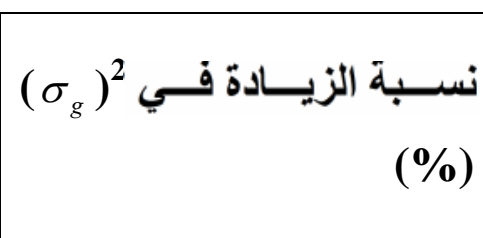 } \\
\hline$(\%)$ & (أقل نسبة السى أعلى نسبة) & \\
\hline
\end{tabular}




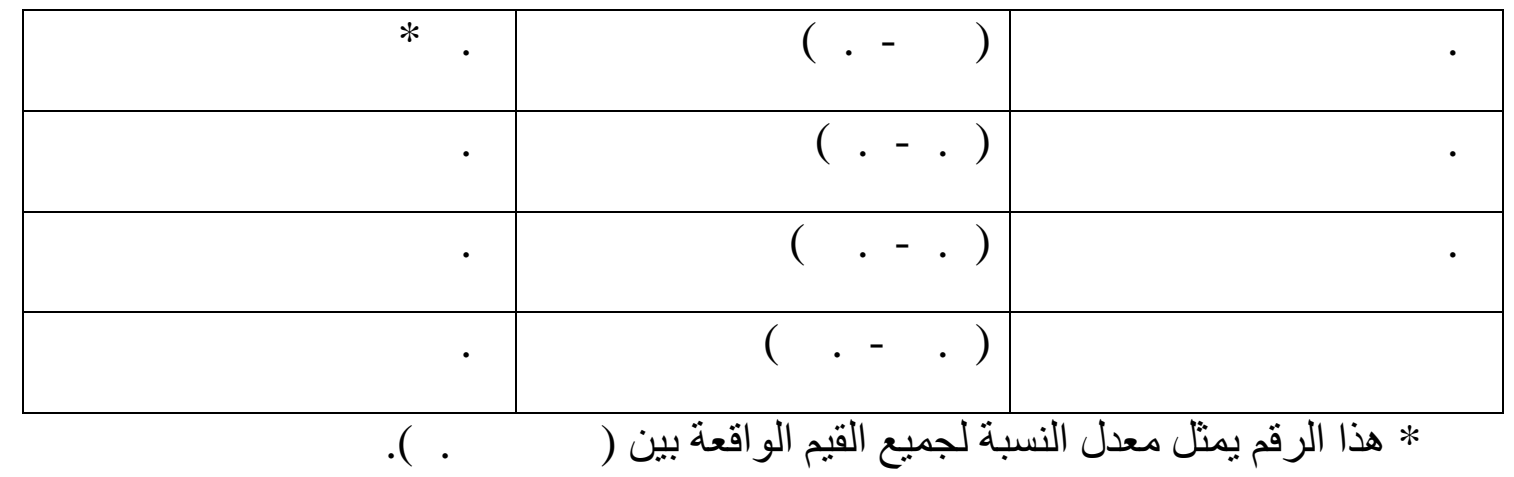

- ـ - تأثير عرض الاعامة (b) على بداية الفثل:

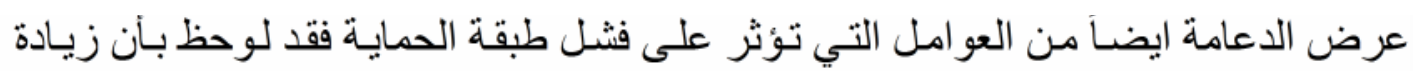

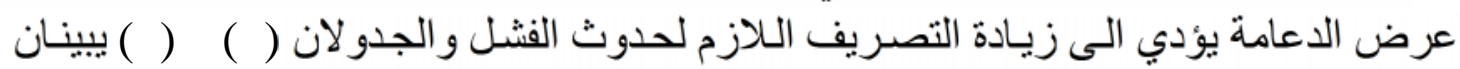

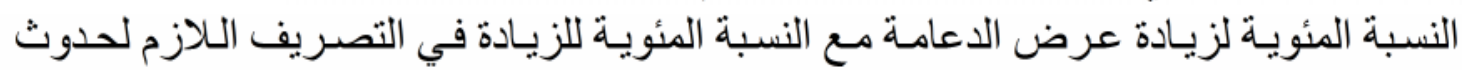

( ) نسبة الزيادة في عرض الدعامات الاسطوانية مع نسبة الزيادة في تصريف الفشل

\begin{tabular}{|c|c|c|}
\hline \multicolumn{2}{|c|}{ نسبة الزيادة في تصريف الفثل (Q) (\%) } & \multirow{2}{*}{ نسـبة الزيــادة فـــ عـرض } \\
\hline معدل نسبة الزيادة (\%) & 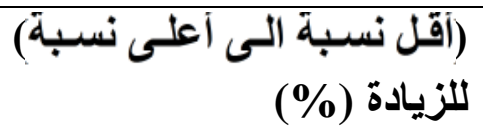 & \\
\hline * & ) & \\
\hline . & $(\cdot-$ & \\
\hline
\end{tabular}

( ) نسبة الزيادة في عرض الدعامات شبه الاسطوانية مع نسبة الزيادة في تصريف

\begin{tabular}{|c|c|c|}
\hline \multicolumn{2}{|c|}{ نسبة الزيادة في تصريف الفشل (Q) (\%) } & \multirow{2}{*}{ نسـبة الزيــادة فــي عـرض } \\
\hline معدل نسبة الزيادة (\%) & 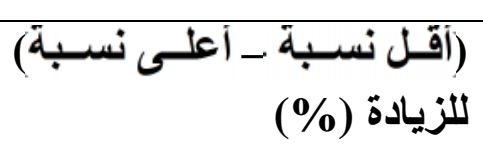 & \\
\hline * & ) & \\
\hline
\end{tabular}




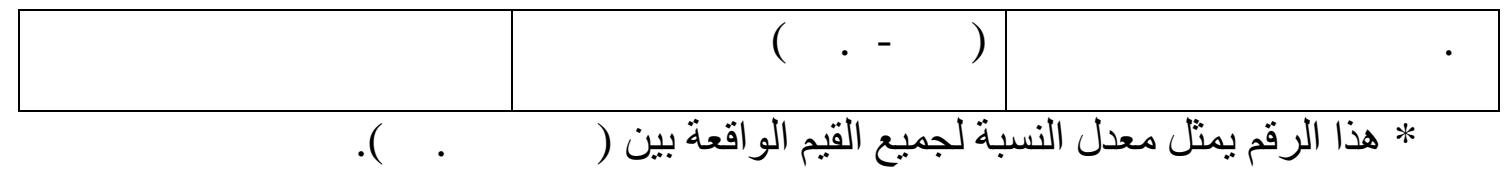

\section{- تغير موقع بداية الفشل فى طبقة الحماية:}

بعد مقارنة الحالات الثناثين لفثل طبقة الحماية و التي هي مقسمة بين الدعامات الاسطو انية

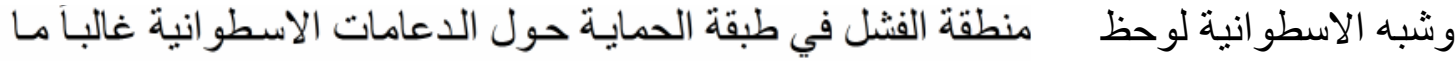

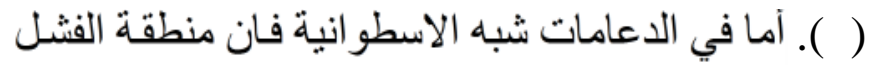

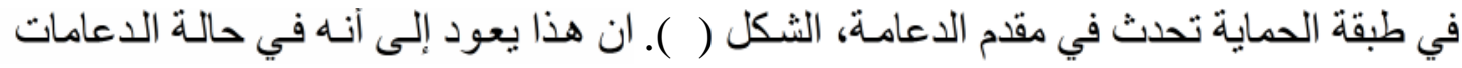
(wake vortices) الاسطو انية فان تأثير

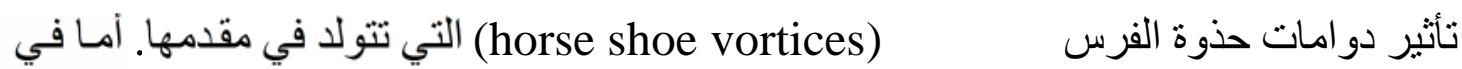

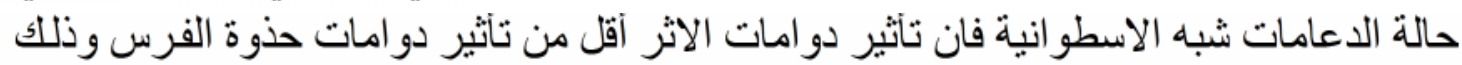

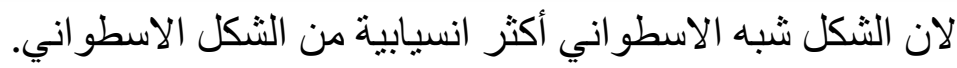

\section{- استتباط علاقة وضعية لحساب الفشل في طبقة الحماية الحجرية حول دعامات الجسور:}

بعد إدخال جميع النتائج المتعلقة بفثل طبقة الحماية الحجريـة حول الدعامـة في البرنـامج الاتية:

(SPSS-10.00)

$$
F_{r o}=0.265\left\{\frac{(k)^{0.659}}{\left(\left(\sigma_{g}\right)^{2}\right)^{0.503}}\left(\frac{b}{y}\right)^{0.083}\right\}
$$

التحديد يساوي ( ). 

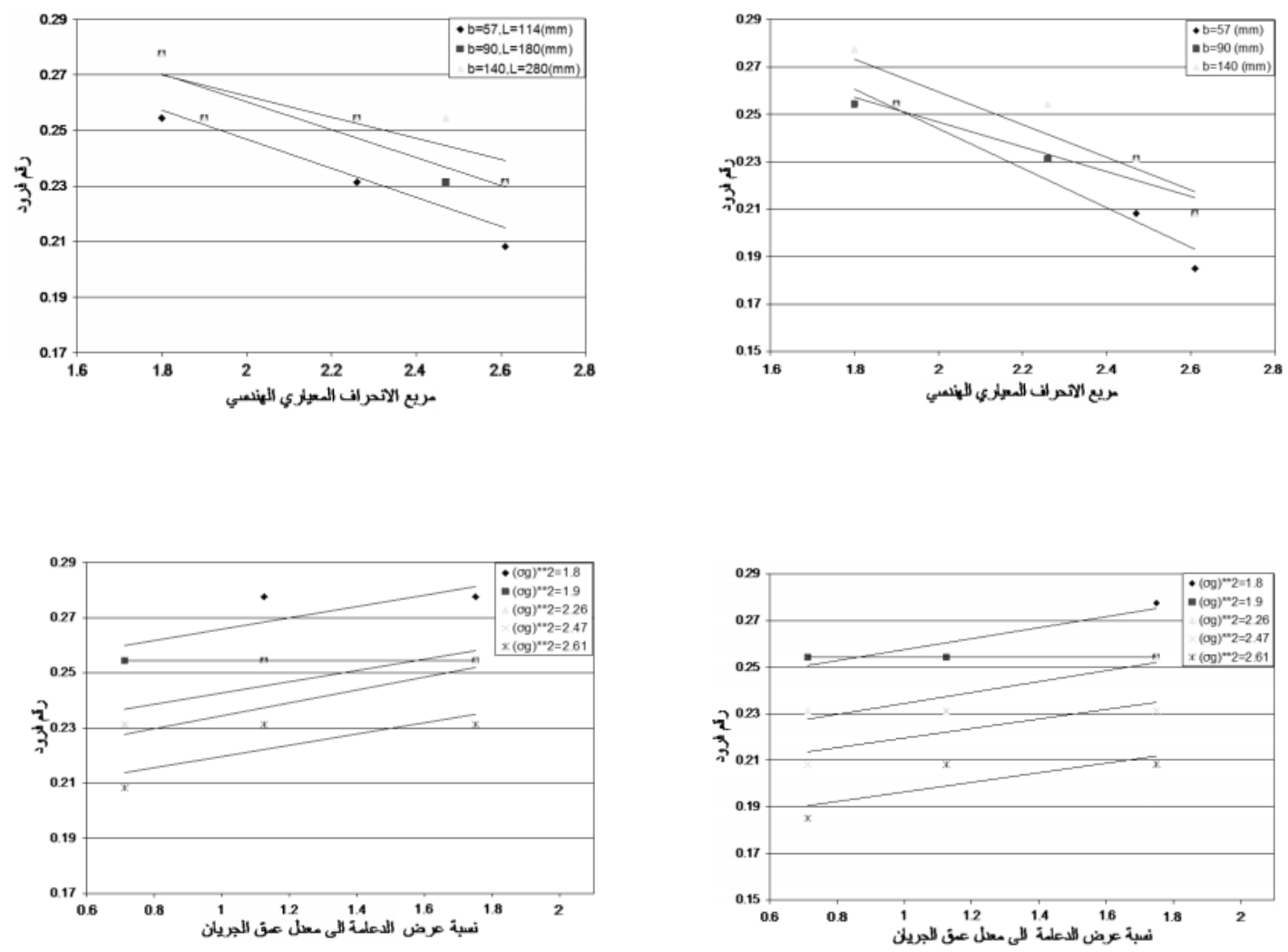

الثكل (T) العلاقة بين نسبة عرض الدعامة إلى معدل الثكل (V) العلاقة بين نسبة عرض الدعامة إلى معدل عمق الجريان (b/y) و) للاعامات شبه الاسطوانية عمق الجريان (b/y) و) (F/y) للاعامات الاسطوانية

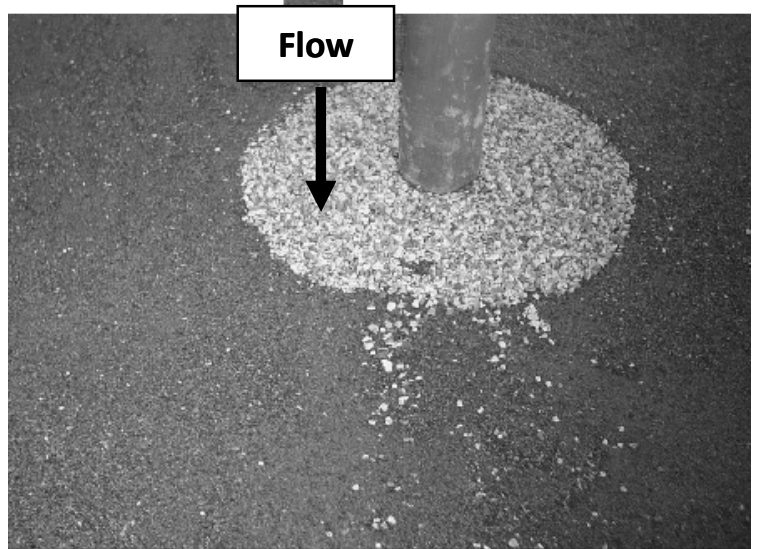

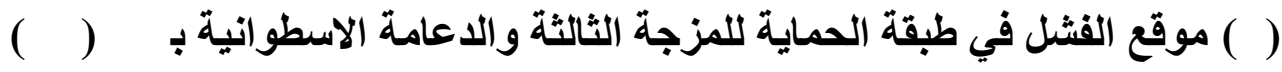
وتصريف ( ) ا (موفع الفي 


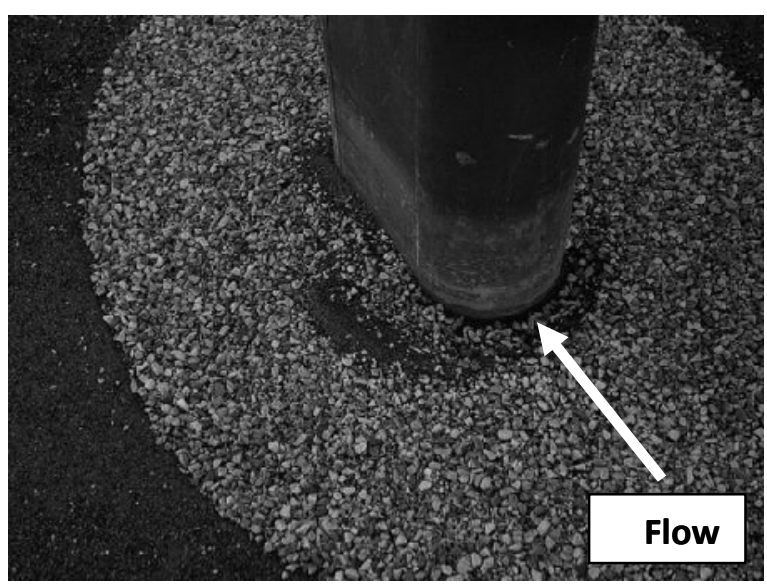

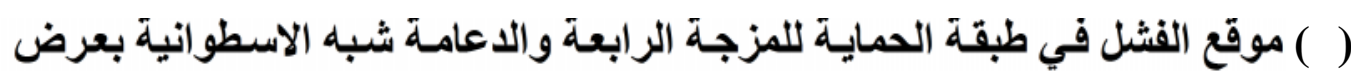

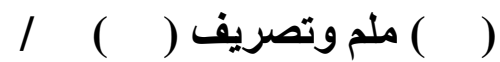

ضمن المحددات التي اجريت فيها تجارب هذا البحث يمكن استتناج ما يلي:

ـ أهمية تدرج حجر الحماية حول دعامات الجسور لحمايتها من النحر الموضـعي وانها عامل

مهم في تحديد استقر اريتها.

ـ تزداد استقر ارية طبقة الحماية كلما زادت نسبة الحجوم الخشنة مقارنة بالحجوم الناعمـة وهذا يمكن الحصول عليه بزيادة عدد حجوم تدرج الحجر.

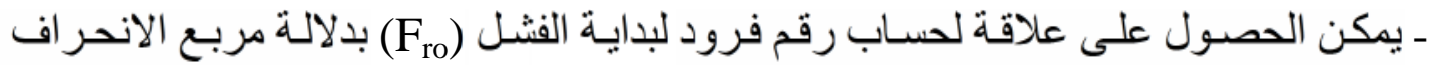

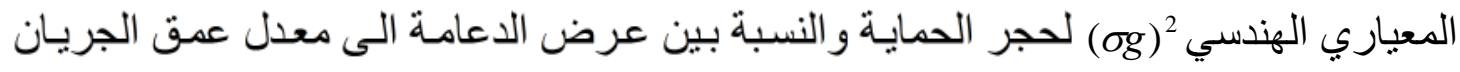

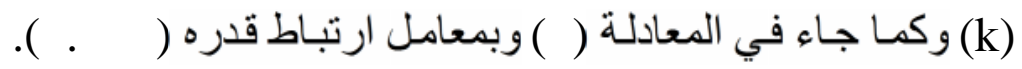

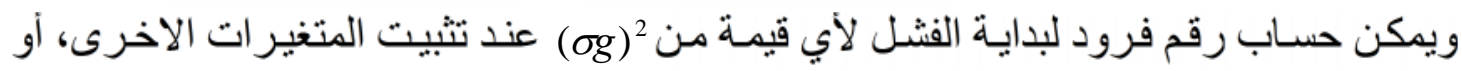
حساب قيمة ${ }^{2}$ (og) عندما تكون قيمة رقم فرود و المتغير ات الاخرى معلو مة.

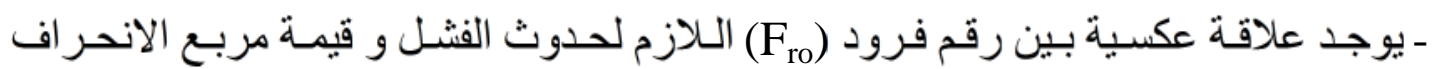

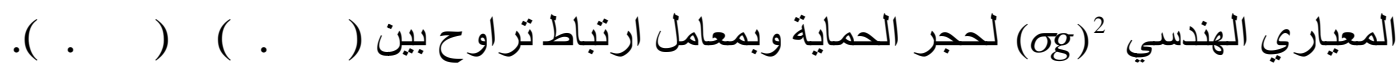
ـ بداية فثل طبقة الحجر حول الدعامات الاسطو انبة يكون في الحافة الخارجية من مؤخرة طبقة الحماية بينما يكون في مقدمة الحافة الداخلية من طبقة الحماية للدعامات شبه الاسطو انية. لاحظ الشكلين ( ) ( ) ( ) 
ـ فثل طبقة الحماية حول الدعامات الاسطو انية يحدث أسر ع من فثل طبقة الحماية حول

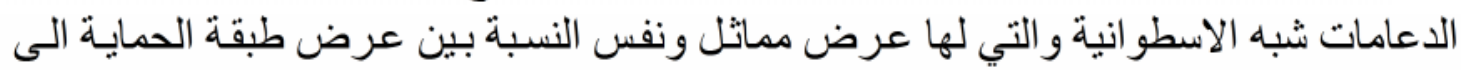

. $\left(\mathrm{C}_{\mathrm{r}} / \mathrm{b}\right)$

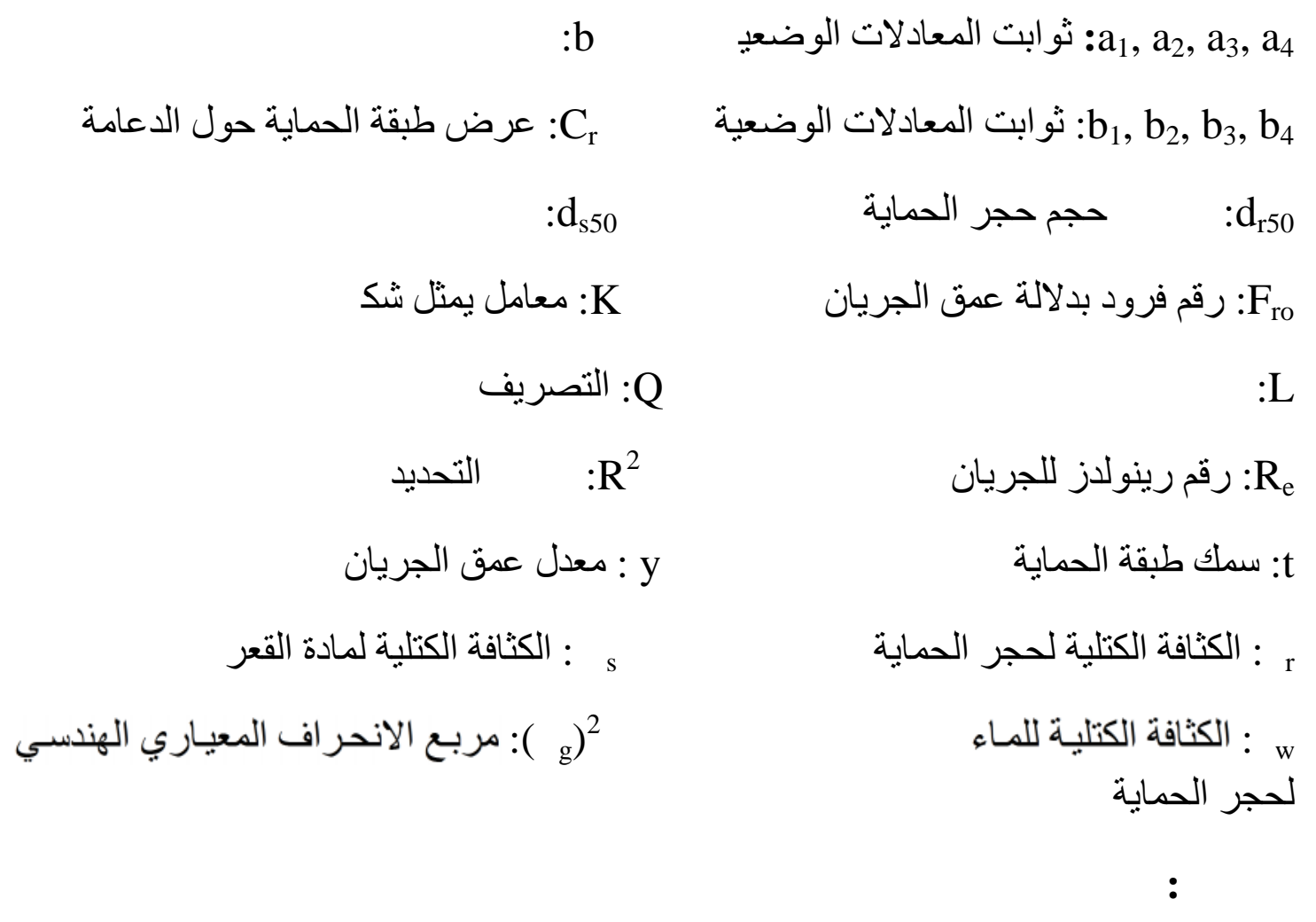

1- Chiew, Y. M. (1995), "Mechanics of riprap failure at bridge piers", Journal of Hydraulic Engineering, ASCE, Vol.121, No. 9, pp. 635 643.

2- Chiew, Y. M., and Lim, F. H. (2000), "Failure behavior of riprap layer at bridge piers under live-bed conditions", Journal of Hydraulic Engineering, ASCE, Vol.126, No.1, pp.43 - 55.

3- Chiew, Y. M., and Lim, F. H. (2004), " Local scour and riprap stability at bridge piers in a degrading channel", Journal of Hydraulic Engineering, ASCE, Vol. 130, No. 3, p.p. 218 - 226.

4- Choi, G. W., Ahn, S. J., Hahm, C. H. ,Kim H. T. and Jeong, S. M. (2002), "Riprap equation for protecting the local scour at bridge piers". URL: http//www.che2002.pl/programme.html

5- Chow, V. T. (1959), "Open channel hydraulics", Mc Graw- Hill Book Company, Inc., New York, USA. 
6- DACE, Department of the Army, Corps of Engineers (2003), "Bid for construction of flood protection project", Van Bibber Creek, Arvada, Colorado, USA.

URL:http//www.floodaily.com/archive/2003/07-july31-jul-2003lydoc.htm

7- Dunham, C. W. (1950), "Foundations of structures", Mc Graw-Hill Book Company, Inc., New York, USA.

8- FHWA, Federal Highway Administration (1995), "Evaluating scour at bridges", Hydraulic Engineering Circular (HEC) No.18, 3rd Edition, Washington, D.C., USA.

9- Johnson, P. A., and Forico, E. F. (1994), "Scour around wide piers in shallow water", Transportation Research Board Record 1471, Transportation Research Board, Washington, D.C., USA.

10- Kamil, H. M. Ali, and Othman Karim (2002), "Simulation of flow around piers", Journal of Hydraulic Research, IAHR, Vol.40, No. 2, p.p. 161-173.

11- Kothyari, U. C., and Ranga Raju (2002), "Influence of cohesion on scour around bridge piers", Journal of Hydraulic Research, IAHR, Vol.40, No. 6, p.p. 717-729.

12- Lauchlan Christine S., and Melville, B. W. (2001), "Riprap protection at bridge piers", Journal of Hydraulic Engineering, ASCE, Vol. 127, No. 5, p.p. $412-418$.

13- Lim, F. H., and Chiew, Y. M. (2001), "Parametric study of riprap failure around bridge piers", ASCE, Journal of Hydraulic Research, IAHR, Vol. 39, No.1. P.P. 61-72.

14- Maynord, S. T. (1998), "Sizing dumped rock riprap", Journal of Hydraulic Engineering, ASCE Vol. 124, No.6, p.p. 652-655.

15- Shen, H. W. (1971), "River Mechanics", Vol. 2, Published by, H. W. Shen, P.O.Box 606, Fort Collins, Colorado, USA.

16- Simons, B. D. and Senturk, F. (1977), "Sediment transport technology", Water Resources Publication, Fort Collins, Colorado, USA.

17- SP, (1998), "Slope protection", revised.

URL:http://www.nwk.usace.army.mil/local-protection/pdf/slopeprot.pdf 
18- USCOE, U S Army Corps of Engineers (1991), "Hydraulic design of flood control channels", Engineer Manual 1110-2-1601, July.

19- USGS (2000), "Scour at bridges", Internet Report, MassachusettsRhode Island, USA.

URL: http://www.usgs.gov/osw/techniques/workshop/mueller.html

20- USGS (2001), "Its not just water under the bridge", Open House: Bridge Scour, USGS 0n-line Resources.

URL:http://www.usgs.gov/2001openhouse/exhibits/35-bridgescour.html

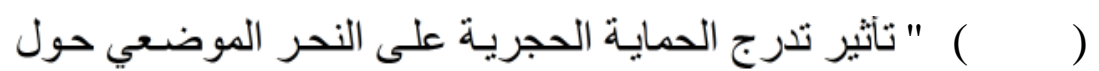

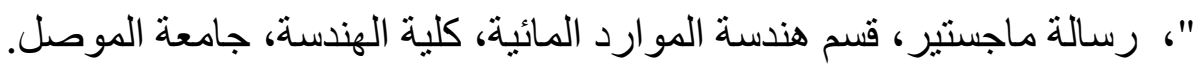

$$
\text { تم اجراء البحث في كلية الهندسة - }
$$

